\title{
Hypertrophic osteoarthropathy without radiographic evidence of new bone formation
}

\author{
RAJNI AMIN \\ M.B., B.S., M.R.C.P., F.R.C.R., D.M.R.T. \\ Radiotherapy Department, Royal Devon and Exeter Hospital, Exeter
}

\begin{abstract}
Summary
A 70-year-old man with florid symptoms of hypertrophic osteoarthropathy for over a year presented without radiographic evidence of new bone formation. His symptoms improved after exploratory thoracotomy, but recurred with lesser severity a year later with tumour recurrence on the chest wall. Absence of new bone formation was again demonstrated radiologically as well as by isotope scan.
\end{abstract}

KEY wORDS: hypertrophic osteoarthropathy, lung adenocarcinoma.

\section{Introduction}

The syndrome of hypertrophic osteoarthropathy was described by Bamberger (1889) and Marie (1890). It is characterized by clubbing of fingers and toes, arthralgia and signs of autonomic disorders, such as sweating, flushing, and blanching of the skin. It has been reported in association with a variety of diseases, including neoplasms of lung, oesophagus, thymus and stomach and intrathoracic Hodgkin's disease (Fischer, Singer and Feldman, 1964; Shapiro and Zvaifler, 1973). The pathogenesis is still uncertain. It seems probable that the autonomic nervous system is involved as the condition may be abolished after resection of the vagus nerves. Even thoracotomy, without removal of the tumour, may sometimes be effective (Crofton and Douglas, 1981).

Radiologically there is sub-periosteal new bone formation in the distal diaphyseal regions of long bones, and less commonly of the phalanges, maxillae, mandible and ribs. Skeletal imaging displays pericortical linear accumulation of tracer along the long bones and proximal phalanges, sometimes referrea to as the 'parallel tract' or 'double stripe' sign. Associated synovitis may produce increased uptake in juxtaarticular bone. A case of hypertrophic osteoarthropathy is described here with no radiological evidence of new bone formation.

\section{Case report}

A 70-year-old man presented in August 1979 with a one year history of disabling pains in ankles, knees, hips, shoulders and wrists. He also had difficulty in getting up from a chair, and he could not kneel down. He had no chest symptoms whatsoever. His pain wos relieved by an aspirin-containing compound. Cliniogl examination revealed marked clubbing of finges (Fig. 1) and toes. There was pretibial thickening of tissues with periarticular swelling of the ankles.0 rest of the examination was normal.

Chest radiograph showed a mass in the anterior segment of the left upper lobe with hilar prominence, and elevation of the left hemi-diaphragm. Radio graphs of bones of hands, arms, shoulders, feet, leg hips and skull were normal, and in particular there was absence of new bone formation.

Bronchoscopy revealed bleeding from the left upper lobe bronchus. Mediastinoscopy was normat On 10 September 1979 he underwent exploratory thoracotomy, at which there was a hard plaque of tissue adherent to the apex of the pleural cavity lying anteriorly close to the mediastinum, and in thes region there was an $8 \times 7 \mathrm{~cm}$ tumour of the anterior segment of the left upper lobe. There was invasiog and adhesion of tumour to the arch of aorta which precluded resection. No attempt to strip off the tumour nerve supply or to resect branches of the vagus nerve to the left lung was made. Histolog. showed infiltration by adenocarcinoma. His joint pains resolved completely on the first postoperative day. He was referred for radiotherapy a week latef

Following a course of radiotherapy he remaines well till June 1980 when he developed localized pai from recurrence along the lower half of the thoracer tomy scar. His pain and the recurrences subside with radiotherapy. In October 1980, he developea recurrence over his left lower chest laterally. At this time apart from local pain he also had recurrence $\mathcal{G}$ the symptoms of bone and joint pains main 


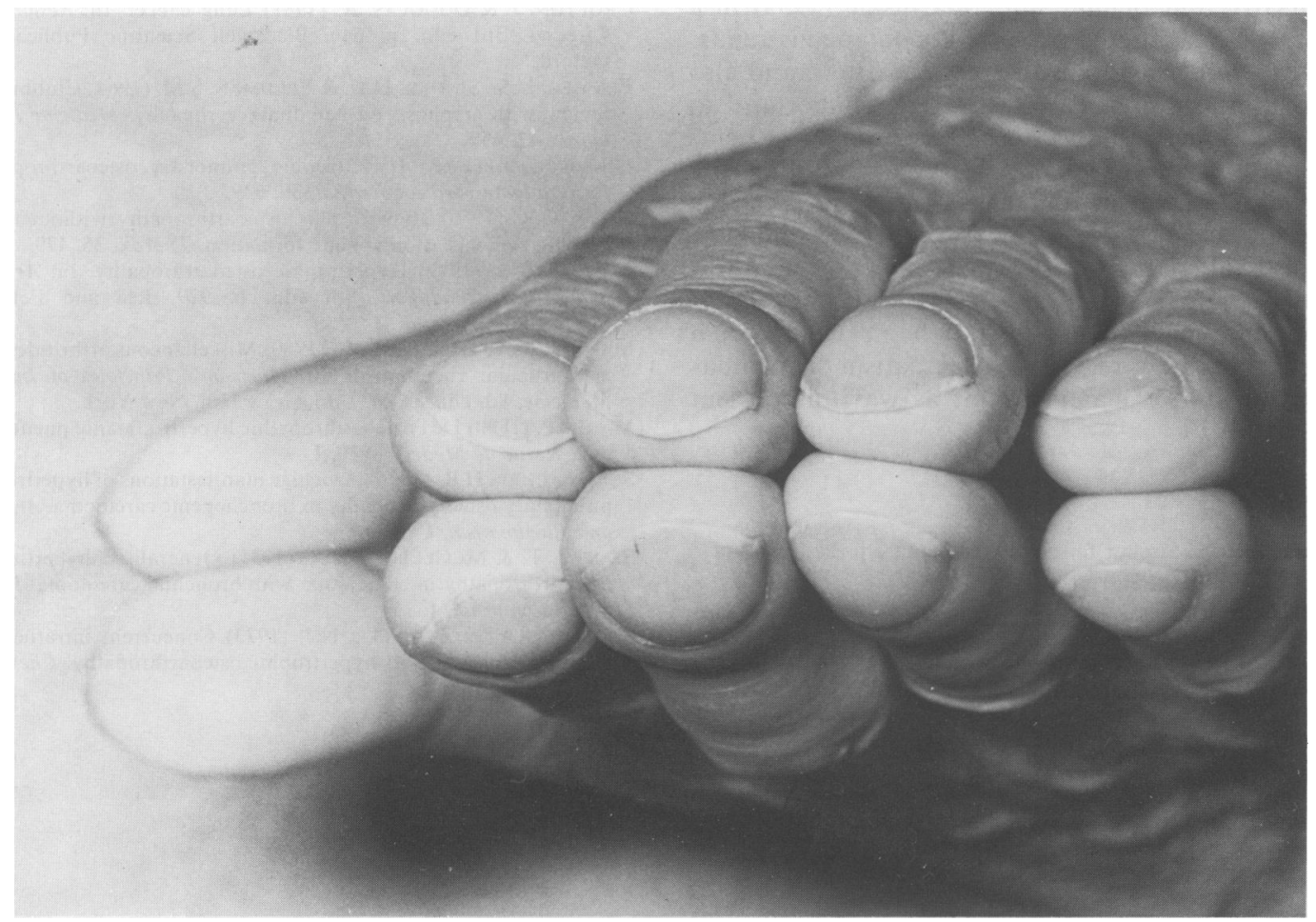

FIG. 1. Shows marked clubbing.

confined to shins and ankles. Limited X-rays of the leg bones yet again failed to reveal any new bone formation. A skeletal isotope scan was normal apart from minimally increased uptake in the mid-thoracic region which was ascribed to metastases in spine.

His chest pain was relieved with further radiotherapy, and his bone and joint pains subsided concurrently without any specific therapy. In February 1981 he developed pain along the upper half of the thoracotomy scar, from the recurrence along the upper end of the scar. At this juncture he left the district.

\section{Discussion}

Hypertrophic osteoarthropathy occurs in 5-10\% of patients with primary intrathoracic malignancies, notably bronchogenic carcinomas and pleural tumours, but is very rare with metastatic tumours of lung (Mannik and Gilliland, 1980). It may precede the onset of symptoms by several months (Semple and McCluskie, 1955), and occasionally periosteal changes evolve without symptoms. Although Ginsberg (1963) suggested that periostitis of long bones must be present for diagnosis, typical periosteal changes may not be present in hypertrophic osteoarthropathy of relatively recent onset, or as in the present case with long duration of symptoms. Horn (1980) described a case of hypertrophic osteoarthropathy in a patient without radiographic evidence of new bone formation. The duration of symptoms in his case was less than three months, which is possibly not long enough for periosteal changes to develop. Schumacher (1976) and co-workers reported a patient with bronchogenic carcinoma who had no joint effusion but periarticular tenderness and clubbing for three months with normal X-rays. Typical periosteal elevation developed after six months.

The present case portrays an unusual manifestation of hypertrophic osteoarthropathy. Despite florid long-standing symptoms there was no radiological evidence of new bone formation: and recurrence of symptoms almost a year later was again not associated with new bone formation radiologically or on radionuclide bone scanning which is considered a sensitive detector of new bone formation.

The other interesting feature about this patient was that his bone and joint pains resolved dramatically with thoracotomy and biopsy of the tumour alone. According to Howell (1979) thoracotomy alone is 
ineffective, but Semple and McCluskie (1955) in a review of 24 patients witnessed spontaneous remission of symptoms, following certain drugs, and also after thoracotomy. It is extremely important to consider hypertrophic osteoarthropathy in patients with painful joints and/or periarticular swelling as it may allow diagnosis of lung cancer at a resectable stage. If acute polyarthritis precedes clubbing or radiological changes of hypertrophic osteoarthropathy, by months or years, search for an asymptomatic pulmonary neoplasm may be neglected. Such patients are often treated for rheumatism or rheumatoid arthritis for many months as was this present case.

\section{Acknowledgment}

I thank Mrs C. Strelow for typing the manuscript.

\section{References}

Bamberger, E. (1889) In Protokoll der K.K. Gesellschaft der Aerzte in Wein. Wiener Klinische Wochenschrift, 2, 226.
Crofton, J. \& Douglas, A. (1981) Lung cancer. In: Respirataxy Diseases, 3rd edn, p. 646. Blackwell Scientific Publications, Oxford.

FisCher, D.S., Singer, D.H. \& FeldMAN, S.M. (1964) Clubbing review with emphasis on hereditary acropachy. Medicine (BdPimore), 43, 459.

GINSBERG, J. (1963) Hypertrophic pulmonary osteoarthropat Postgraduate Medical Journal, 39, 639.

HORN, C.R. (1980) Hypertrophic osteoarthropathy without rad $\frac{\Phi}{10}$ graphic evidence of new bone formation. Thorax, 35, 479.

HowELL, D.S. (1979) Hypertrophic osteoarthropathy. In: Arthrigis and Allied Conditions. 9th edn, p. 979. Lea and Febiget. Philadelphia.

MANNIK, M. \& GILLILAND, B. (1980) Miscellaneous arthritides and extraarticular rheumatism. In: Harrison's Principles of Internd Medicine, 8th edn, p. 2077. McGraw Hill, New York.

MARIE, P. (1890) De l'osteoarthropathic hypertrophiante pneumoख que. Revue de Medecine, 10, 1.

SCHUMACHER, H.R. (1976) Articular manifestations of hypertrop pulmonary osteoarthropathy in bronchogenic carcinoma. Arthrif and Rheumatism, 19, 629.

SEMPLE, T. \& MCCLUSKIE, R.A. (1955) Generalised hypertroplơ osteoarthropathy in association with bronchial carcinoma. British Medical Journal, 1, 754.

ShaPIRo, R.F. \& ZVAIFLER, N.J. (1973) Concurrent intrathoraeic Hodgkin's disease and hypertrophic osteoarthropathy. Chest, 63 , 912.

(Accepted 18 May 1982) 